\title{
Incidence, Pre-hospital Delay and Prognosis of Acute Myocardial Infarction in Hungary: Population Data from the Hungarian Myocardial Infarction Registry
}

\author{
András Jánosi ${ }^{1}$, Ferenc, Péter Pach ${ }^{2}$, Gergely Erdős ${ }^{2}$, Gabor Csato ${ }^{3}$, György Pápai ${ }^{3}$, and \\ Péter Andréka ${ }^{4}$ \\ ${ }^{1}$ Gyorgy Gottsegen Hungarian Institute of Cardiology \\ ${ }^{2}$ Institute of Advanced Studies Koszeg \\ ${ }^{3}$ National Emergency Service \\ ${ }^{4}$ Gottsegen Gyorgy Orszagos Kardiologiai Intezet
}

July 1, 2021

\begin{abstract}
Aim: To examine the incidence and treatment of acute myocardial infarction (AMI) as well as 30-day and 1-year prognoses of patients in three major regions of Hungary by analysing data from the country's continuous and mandated infarction registry. Methods and results: The total population of Hungary is currently 9.8 million: $39 \%$ live in the eastern region (ER), 31\% in the Central region (CR) and $30 \%$ in the western region (WR). These regions exhibited significant differences in income and people exposed to poverty. Population over 30 years, the age-standardised incidence of AMI was 177.5 (175.7-179.3) per 100,000 person-year. During hospital treatment, $82.5 \%-84.6 \%$ of patients with ST-elevation (STEMI) and $54.8 \%-81.8 \%$ without ST-elevation (NSTEMI) underwent PCI. The total ischaemic time was shortest in WR:221 minutes. In the STEMI group, the 30-day mortality rates of males were lowest in the WR $(\mathrm{p}=0.03)$. If PCI was performed, mortality rates for both sexes were lowest in the WR $(\mathrm{p}<0.01 ; \mathrm{p}=0.04)$. The 1-year mortality rate in the male population who received PCI was lowest in the WR. In the NSTEMI group, the 30-day mortality rate exhibited no differences. Regarding 1-year mortality, those who underwent PCI in the WR showed the lowest mortality. Conclusion: The major regions of Hungary exhibited significant differences regarding the prehospital delay, the incidence, treatment and mortality of AMI. Logistic regression analysis confirmed the independent prognostic significance of the region on the 30-day mortality of patients with STEMI (Hazard ratio $=0.88, \mathrm{p}$ $=0.0114)$.
\end{abstract}

Incidence, Pre-hospital Delay and Prognosis of Acute Myocardial Infarction in Hungary: Population Data from the Hungarian Myocardial Infarction Registry

András Jánosi ${ }^{1}$, M.D., Ferenc Péter Pach ${ }^{2}$, Gergely Erdős ${ }^{2}$, Gábor Csató ${ }^{3}$, György Pápai ${ }^{3}$, Péter Andréka ${ }^{1}$

${ }^{1}$ Gottsegen National Cardiovascular Centre, Budapest, Hungary; ${ }^{2}$ Institute of Advanced Studies, Kőszeg, Hungary, ${ }^{3}$ National Ambulance Service, Budapest, Hungary

Correspondence:

Professor András Jánosi, M.D.

Gottsegen National Cardiovascular Centre

1096 Haller street 29, Budapest, Hungary

Phone: $+361299-8100$, ext. 513 
Fax: $+361299-8181$

E-mail: andras.janosi@gokvi.hu

Personal e-mail: janosiandrasdr@gmail.com

\section{Summary}

Aim : To examine the incidence and treatment of acute myocardial infarction (AMI) as well as 30-day and 1-year prognoses of patients in three major regions of Hungary by analysing data from the country's continuous and mandated infarction registry. Methods and results : The total population of Hungary is currently 9.8 million: $39 \%$ live in the eastern region (ER), 31\% in the Central region (CR) and $30 \%$ in the western region (WR). These regions exhibited significant differences in income and people exposed to poverty. Population over 30 years, the age-standardised incidence of AMI was 177.5 (175.7-179.3) per 100,000 person-year. During hospital treatment, $82.5 \%-84.6 \%$ of patients with ST-elevation (STEMI) and 54.8\%-81.8\% without ST-elevation (NSTEMI) underwent PCI. The total ischaemic time was shortest in WR:221 minutes. In the STEMI group, the 30-day mortality rates of males were lowest in the WR $(\mathrm{p}=$ 0.03). If PCI was performed, mortality rates for both sexes were lowest in the WR $(\mathrm{p}<0.01 ; \mathrm{p}=0.04)$. The 1-year mortality rate in the male population who received PCI was lowest in the WR. In the NSTEMI group, the 30-day mortality rate exhibited no differences. Regarding 1-year mortality, those who underwent PCI in the WR showed the lowest mortality.Conclusion : The major regions of Hungary exhibited significant differences regarding the prehospital delay, the incidence, treatment and mortality of AMI. Logistic regression analysis confirmed the independent prognostic significance of the region on the 30-day mortality of patients with STEMI (Hazard ratio $=0.88, \mathrm{p}=0.0114$ ).

\section{Introduction}

One of the earliest population-based surveys regarding the incidence and treatment of myocardial infarction was initiated and co-ordinated by the World Health Organisation approximately 30 years ago (1). Over the past two decades, many European and Far Eastern countries have launched registries covering the entire population (2-5), and several comparative international studies have been performed (6-9). Due to the varying methodologies of these registries, the comparative evaluation of data has only been possible with certain limitations (10). Following these instances, the European Society of Cardiology initiated the creation of a system that applies a uniform methodology, currently in its pilot phase (11). Such an infarction registry has been available in Hungary since 2014, which is both nationwide and mandated (Hungarian Myocardial Infarction Registry=HUMIR) i.e., in-depth research on the quality parameters of infarction care is possible (12). The mechanisms and funding of healthcare systems are significantly different across countries. Several studies report that depending on an individual's health insurance, social situation, educational background and several other factors, extreme inequalities may occur in the healthcare received between - and even within - certain countries (13-15). According to the statistical system of the European Union, Hungary can be divided into three major socio-economic regions-west Hungary, central Hungary and east Hungary-which exhibit significant sociological and economic differences. According to the data of the Hungarian Central Statistical Office, the GDP per capita is 6,073, 3,581 and 2,722 EUR in the central (CR), western (WR) and eastern (ER) regions, respectively. The proportions of those exposed to poverty and social exclusion are nearly identical in the CR and WR in the total population $(22.4 \%$ vs. $22.5 \%)$; however, this rate is significantly higher in the ER $(30.4 \%)$. The regions and their population data are presented in Figure 1. The aim of this investigation was to compare the incidence, prehospital delay, clinical data, hospital treatment and prognoses of acute myocardial infarction (AMI) in three socio-economically distinct regions of Hungary by analysing data from the national and mandated myocardial infarction registry.

\section{Method}

This study was approved by the Medical Research Council (34858-3/2019/EKU). The Hungarian Myocardial Infarction Registry (HUMIR) is a prospective and comprehensive disease registry for patients with AMI. Since 1 January 2010, this online registry has collected personal and clinical data on consecutive patients 
treated for AMI events in Hungary, a Central European country with 9.8 million residents and a centralised healthcare system. The registry was operated on a voluntary basis between 2010 and 2013; however, by law, registration of all patients with myocardial infarction in the HUMIR has been mandatory for all healthcare providers since 1 January 2014 (statute CCXLVI/2013 of Hungary). Data capture covered 178 structured categories, including prehospital data, medical history, hospital treatment and coronary interventions. The data were recorded in the online database by healthcare professionals and administrators based on hospital documentation, and the information was continuously monitored and validated online. Outcome dataincluding vital status and repeated hospitalisation-were regularly received from the electronic database of the Hungarian Health Care Insurance Fund and National Central Statistical Office.

The aim of the registry is two-fold: to provide quality assurance for patient care and to build a database for research. All hospitals offering acute care participate in the programme, registering approximately 15,000 AMI cases annually; in 2021, the database contained 122,774 patients and 134,986 events. The National Health Insurance Fund is responsible for the financing of healthcare services, whereas acute inpatient care is funded by implementing a system similar to the American Diagnosis Related Groups (16). The diagnosis and treatment protocol for AMI are in line with the current European guidelines (17); thus, the treatment of myocardial infarction with ST-elevation (STEMI) cases is performed at centres prepared for invasive interventions. In Hungary, the capital has six invasive centres and the remaining regions of the country have 14. The operating principles of the centres in the capital and country differ to a certain extent; the six centres in the capital treat patients from the CR between 8 a.m. and 6 p.m. based on a regional principle. Between 6 p.m. and 8 a.m., these centres care for all patients in the region, whereas there is $24 / 7$ care available in all countryside centres. According to the professional protocol for infarction care, the patient has to be transferred directly to a care centre providing cardiac catheterisation in the case of STEMI; if this is not possible, pharmacological anti-thrombotic therapy has to be introduced. In daily clinical practice, pharmacological revascularisation (thrombolysis) is rarely performed (0.1-0.3\% of all cases).

In the case of myocardial infarction without ST-elevation (NSTEMI), the decision concerning the necessity of invasive treatment is based on the patient's prognosis (e.g., GRACE score). Between 1 January 2016, and 31 December 2018, a total of 42,793 AMI cases were registered in the HUMIR database, with 18,435 being STEMI cases. During the 2-year interval (between 1 January 2017 and 31 December 2018), the emergency care data of 6,878 patients treated for myocardial infarction were also available; thus, in this patient cohort, it was possible to examine the time interval between the onset of symptoms and the reopening of the culprit vessel (total ischaemic time, TIT). The time interval between the onset of symptoms and the calling of emergency services was examined, along with the different time intervals of the emergency care process: arrival to location (T1), treatment on-site (T2) and time interval between transferring the patient from the original location to the hospital (T3). Time values were indicated by median time and quartiles, and we analysed the allcause mortality of all cases observed until 30 November 2019. The $\mathrm{R}$ statistical programme package (version 3.6.3; https://www.r-project.org/about.html) was used for data processing; in the descriptive statistical analysis, we represented the distribution of category variables by frequency (and proportion value) and continuous variables by mean value (distribution) and median treatment time (quartiles). For the comparative analysis of the examined groups, we applied the Wilcoxon test for continuous variables in two-sample cases and the Kruskal-Wallis test in multiple-sample cases; for categorical variables, the Chi-squared test was used (WHO No. 95). For categorical variables, regional differences were evaluated using the Chi-squared and accompanying post-hoc test. The calculations of age-standardised rates in the particular regions were calculated by applying the direct method based on the official WHO guidelines. For the standard age group distribution, we applied the European age standard. When analysing fatalities, we used the stratified Cox-PH regression model (18). Because one of the major conditions of the applicability of the Cox regression model was not met (with the help of the Schoenfeld test, we determined that the risk ratios of the examined factors were not time-independent), the time variable was divided into three parts based on 30 and 365 days. Thus, this study aimed to determine the risk ratios of individual factors.

\section{Results}




\section{Completeness of registration}

During the years included in the study (2016, 2017 and 2018), 90.2\%, 93.8\% and 93.6\% of events treated and funded as infarction diagnoses appeared in the registry database, respectively.

Number and geographical distribution of invasive centres in Hungary

There are six invasive centres in the CR and seven in each of the other two regions, with 418,000 inhabitants per centre in the WR, 505,000 in the CR and 545,000 in the ER.

\section{Patient characteristics}

The average age, sex ratio, events included in the medical history and comorbidities of patients treated for different types of infarction are summarised in Table $\mathbf{1}$. In the case of STEMI, patients in the CR were significantly older than those in the WR and ER. Compared with the other two regions, prior infarction was most common in the CR, whereas stroke was the most common prior disease in the ER; both hypertension and peripheral artery disease were more common in the WR and ER than in the CR. The incidence of diabetes was significantly higher in the WR than in the other two regions.

In the NSTEMI group, patients were again oldest and prior myocardial infarction was most common in the CR. Regarding comorbidities, statistically significant differences in incidence were not clinically important, except the incidence of peripheral artery disease, in which a $3 \%$ lower incidence was found in the WR than in the other regions.

Incidence of STEMI and NSTEMI in the investigated regions

The age-standardised incidence (confidence intervals) of AMI in the population over 30 years per 100,000 person-years was 177.5 (175.7-179.39). There were some differences among regions: WR: 171.4 (168.3-174.5), CR: 179.1 (175.9-182.4), ER: 181 (178.2-183.9).

Ratios of invasive treatments for different types of myocardial infarction per region

The ratios of invasive treatments were significantly greater for STEMI than for NSTEMI in all regions. The percentages of revascularisation performed in the STEMI group in the WR, CR and ER were 83.0\%, 82.5\% and $84.6 \%$, respectively; in the NSTEMI group, revascularisation was performed in $54.8 \%, 55.7 \%$ and $58.8 \%$ of patients, respectively. In the ER, the ratio of revascularisation was significantly higher than in the other two regions $(\mathrm{p}<0.05)$.

Patient delay, prehospital response time and types of infarction per region

Patient delay and emergency care times were available for 6,878 patients treated for infarction; 3,264 (47.5\%) were hospitalised for STEMI (median times are summarised in Table 2 according to diagnosis and regional division). For both types of infarction, the time interval between T1 and T2 was longest in the CR, whereas T3 was the shortest in this region. The median emergency care times were longest in the CR for the STEMI group and the ER for the NSTEMI group (Figure $\mathbf{2} \mathbf{a}-\mathbf{b}$ ). TIT was examined in the 3,264 patients with STEMI treated with PCI; unfortunately, this time interval significantly exceeded the optimal value in all three regions. Similar TIT values were observed in the WR and CR (221 and $225 \mathrm{~min}$, respectively), and it was $262 \mathrm{~min}$ in the ER. Patient delay was determined in minutes per region (q1; q3): WR, 91 (37.25; 265.5); CR, $97(34.0 ; 265.5)$ and ER, $111(39.5 ; 292.5)$. More than $40 \%$ of the TIT was caused by patient delay.

Ratios of pharmacological treatment for secondary prevention per region

Figure 3 shows the pharmacological treatment for secondary prevention recommended upon hospital discharge per region. The recommended ratio of the drugs for both types of infarction and in all three regions was high. The rates of RAAS inhibitor treatment for STEMI were significantly lower in the ER than in the CR (78.7\% vs. $83.6 \%$ ), but the ratios for beta-blocker therapy were lower in the WR than in the other two regions for both types of infarction.

Follow-up duration and 30-day and 1-year mortality data for both myocardial infarction per region 
Patients were followed up for a total of $678 \pm 431$ days; all-cause mortality data are summarised in Table 3 . All-cause mortality rates for both sexes and both types of infarction were lower when PCI was performed on the patient. In numerous cases, the analysis confirmed more favourable mortality data in the WR. Regarding the STEMI group, male patients and patients who underwent PCI, mortality was lowest in the WR at both examined times $(\mathrm{p}=0.03, \mathrm{p}<0.01)$. In female patients of the same group-independent of treatment received (PCI vs. no PCI) - mortality was lowest in the WR at both examined times; a significant difference was only found in the 1-year mortality rate of patients treated via PCI $(\mathrm{p}=0.04)$.

No statistically significant differences were observed regarding the 30-day mortality rate of the NSTEMI group among the three regions; however, the lowest values were detected in the ER in males and the WR in females. At the 1-year checkpoint, females who underwent PCI in the WR exhibited significantly lower mortality values than in the CR $(\mathrm{p}<0.01)$. Upon comparison between females in the STEMI and NSTEMI groups at the 30-day checkpoint, mortality rate was higher in the STEMI group than in the NSTEMI group. The mortality rate among males showed no differences between the STEMI and NSTEMI groups; however, at the 1-year checkpoint, the NSTEMI group had a higher mortality rate than the STEMI group for both sexes (males vs. females, NSTEMI: $22.3 \%$ vs. $17.2 \%$; STEMI; $28.2 \%$ vs. $26.1 \%$ ).

\section{Comparison of Kaplan-Meier survival curves and Cox regression analysis of mortality data}

Figures 4 and $\mathbf{5}$ show the survival curves of patients with NSTEMI and STEMI. Considering confidence intervals, we found that the differences among the regions were borderline significant in the NSTEMI group, whereas the 1-year survival of the STEMI group (Figure 4 ) was significantly better in the WR. As several factors influence survival, multivariate analysis was also performed using Cox regression analysis. During multiple factor analysis, age, sex, prior ischaemic events (infarction or stroke), presence of comorbidities, revascularisation performed during treatment and region of settlement were considered.

In the STEMI group, age and history of stroke, comorbidities, diabetes mellitus and peripheral artery disease significantly worsened survival rates throughout the entire follow-up period, whereas the survival rates of patients who received PCI treatment were significantly better than of those who did not receive invasive treatment at all checkpoints. In the NSTEMI group, age and history of stroke, diabetes mellitus and peripheral artery disease significantly worsened patient outcomes throughout the entire follow-up period, whereas PCI treatment significantly lowered their mortality rates. When analysing both types of infarction together, age and history of stroke, diabetes mellitus and peripheral artery disease were confirmed to have a negative impact on survival rate, whereas PCI treatment showed a positive effect.

Logistical regression analysis confirmed several factors influencing survival (Figures 6 and 7); among them, the region with independent importance: 30-day mortality; in the case of STEMI, the risk of death in the WR was $12 \%$ lower than in the ER (Hazard ratio $=0.88, \mathrm{p}=0.01144$ ). At the 1-year checkpoint the region did not influence survival. Analysis of the 1-year survival data of the NSTEMI group showed that the mortality risk of patients living in the CR was $13.9 \%$ lower than those in the ER (Hazard ratio $=0.861 ; \mathrm{p}=0.0218$ ).

\section{Discussion}

The Seven Countries Study is a significant milestone in epidemiological research on cardiovascular diseases. The study, which included seven countries, was the first to confirm that the incidence of coronary disease was significantly different among countries (19), with the incidence of the disease is exceptionally high in Finland. Further research also revealed a significant difference between the WR and ER of Finland (20). Knowledge of the shocking extent of this difference, as well as local initiative, resulted in the launch of the North Karelia Project, which eventually demonstrated that the incidence of myocardial infarction could be decreased by the population-level control of the risk factors (21). Several publications appeared following these classical studies, whose authors called attention to regional differences regarding the incidence and treatment of myocardial infarction (13, 22-29). Upon examining the same problem, several articles underlined the role of the social environment of the population (30-33).

In a meta-analysis of several studies, Manrique-Garcia et al. (14) found that the incidence of myocardial 
infarction was influenced both by the social and economic status of the population, as well as their educational background, i.e. the incidence of myocardial infarction was higher in underprivileged people. Israeli authors compared the hospital treatment data of Israeli-born and immigrant patients treated for myocardial infarction, along with their short- and long-term mortality rates. Israeli-born citizens showed a higher ratio of revascularisation for STEMI, whereas their short- and long-term mortality rates were lower. Among the immigrant patients, the highest 10-year mortality rates were detected in those who migrated from Yemen, Southern Europe and the Balkans; the prognoses of Central European and Pakistani immigrants showed no differences (34). For the complex examination of infarction care, continuous registers were created in several European countries $(2,3,5)$, enabling quality assurance for care, as well as monitoring of changes in treatment. Based on population data, it has become possible to compare data from different countries $(6,8$, 9); nevertheless, when evaluating the data, methodological differences pose a problem (10).

The European Society of Cardiology initiated a European registry programme to uniformly follow major cardiological diseases in 2019, called Unified Registries On Heart Care Evaluation and Randomised Trials (11). In the present study, we compared the data of the three major regions of Hungary with respect to the incidence of myocardial infarction, patients' clinical data, emergency care and prognosis. Both types of infarction were most common ( $42.9 \%$ and $36.3 \%$ of all cardiovascular events), and the incidence of myocardial infarction was highest in the ER. Compared with US data from 2008, the incidence of myocardial infarction for the total population was higher in Hungary: $177.5 \%$ vs. 168 per 100,000 person-years (35). Stroke and peripheral artery disease were also the most common diseases in the medical history of patients living in the ER, wherein TIT was longest (262 min). Delays until revascularisation were primarily caused by patient delay as the most unfavourable values in emergency care were found in the CR (in the case of T1 and T2 values). The revascularisation ratio was $84.6 \%$ in the STEMI group and $58.8 \%$ in the NSTEMI group.

\section{Limitations of the study}

We examined regional differences in the care and prognosis of patients treated for myocardial infarction. The differences found are apt to draw attention to the importance of the issue. At the same time, however, there are exceptionally large socio-economic differences within large regions (university town vs. hard-to-reach village), so it is necessary to analyse data from smaller territorial units to examine access to modern care.

\section{Conclusion}

Among the three included regions of Hungary, significant differences were detected in the incidence of AMI, TIT of patients with STEMI and their mortality rates. Additionally, logistic regression analysis confirmed the independent prognostic significance of the region regarding 30-day mortality; however, further research is necessary to explore the data of smaller regional units with respect to infarction treatment, with particular regard to accessing up-to-date care and secondary prevention.

Acknowledgments: We would like to thank all participants of HUMIR and Editage (www.editage.com) for English language editing.

Conflict of Interest: none declared.

Data availability: The data from HUMIR that support the findings of this study are available on reasonable request to the corresponding author.

\section{References:}

1. Tuomilehto J, Kuulasmaa K. WHO Monica Project assessing CHD mortality and morbidity. Int J Epidemiol 1989;18:S38-S45.

2. Birkhead J, National Audit of Myocardial Infarction Project. Where are we today? Early results from MINAP, the National Audit of Myocardial Infarction Project. Heart 2003;89 Suppl 2:ii13-5; discussion ii35-7.

3. Jernberg T, Attebring MF, Hambraeus K, Ivert T, James S, Jeppsson A et al The Swedish Websystem for enhancement and development of evidence-based care in heart disease evaluated according 
to recommended therapies (SWEDEHEART). Heart 2010;96:1617-1621.

4. Sim DS, Jeong MH, Kang JC. Current management of acute myocardial infarction: experience from the Korea Acute Myocardial Infarction Registry. J Cardiol 2010;56:1-7.

5. Wilkinson C, Weston C, Timmis A, Quinn T, Keys A, Gale CP. The Myocardial Ischaemia National Audit Project (MINAP). Eur Heart J Qual Care Clin Outcomes 2020;6:19-22.

6. Blöndal M, Ainla T, Eha J, Loiveke P, Marandi T, Saar A et al Comparison of management and outcomes of ST-segment elevation myocardial infarction patients in Estonia, Hungary, Norway and Sweden according to national ongoing registries. Eur Heart J 2020;41Suppl 2:1604.

7. Edfors R, Jernberg T, Lewinter C, Blöndal M, Eha J, Lõiveke P et al Differences in characteristics, treatments and outcomes in patients with non-ST-elevation myocardial infarction -novel insights from four national European continuous real-world registries. European Heart Journal - Eur Heart J Qual Care Clin Outcomes 2021 Feb 19;qcab013. doi: 10.1093/ehjqcco/qcab013. Online ahead of print.

8. Tern PJW, Ho AKH, Sultana R, Ahn Y, Almahmeed W, Brieger D et al. Comparative overview of ST-elevation myocardial infarction epidemiology, demographics, management, and outcomes in five Asia-Pacific countries: a meta-analysis. Eur Heart J Qual Care Clin Outcomes 2021;7:6-17.

9. Chung SC, Gedeborg R, Nicholas O, James S, Jeppsson A, Wolfe C et al Acute myocardial infarction: a comparison of short-term survival in national outcome registries in Sweden and the UK. Lancet 2014;383:1305-1312.

10. Aktaa S, Gale CP. Regional differences in ST-segment elevation myocardial infarction care and outcomes: a call for multi-national cardiovascular registries. European Heart Journal - Quality of Care and Clinical Outcomes 2020;7:1-2.

11. Wallentin L, Gale CP, Maggioni A, Bardinet I, Casadei B. EuroHeart: European Unified Registries On Heart Care Evaluation and Randomised Trials. Eur Heart J 2019;40:2745-2749.

12. Janosi A, Ferenci T, Ofner P, Lupkovics G, Becker D, Falukozy J et al Does gender have prognostic value among patients with myocardial infarction? Analysis of the data from the Hungarian Myocardial Infarction Registry. J Womens Health (Larchmt) 2018;27:1491-1498.

13. Bonow RO, Grant AO, Jacobs AK. The cardiovascular state of the union: confronting healthcare disparities. Circulation 2005;111:1205-1207.

14. Manrique-Garcia E, Sidorchuk A, Hallqvist J, Moradi T. Socioeconomic position and incidence of acute myocardial infarction: a meta-analysis. J Epidemiol Community Health 2011;65:301-309.

15. Kampfer J, Yagensky A, Zdrojewski T, Windecker S, Meier B, Pavelko M et al Long-term outcomes after acute myocardial infarction in countries with different socio-economic environments: an international prospective cohort study. BMJ Open 2017;7:e012715.

16. Boncz I, Nagy J, Sebestyen A, Korosi L. Financing of health care services in Hungary. Eur J Health Econ 2004;5:252-258.

17. Ibanez B, James S, Agewall S, Antunes MJ, Bucciarelli-Ducci C, Bueno H et al 2017 ESC Guidelines for the management of acute myocardial infarction in patients presenting with ST-segment elevation: The Task Force for the management of acute myocardial infarction in patients presenting with ST-segment elevation of the European Society of Cardiology (ESC). Eur Heart J 2018;39:119-177.

18. Bellera CA, MacGrogan G, Debled M, de Lara CT, Brouste V, Mathoulin-Pélissier S. Variables with time-varying effects and the Cox model: Some statistical concepts illustrated with a prognostic factor study in breast cancer. BMC MedRes Methodol 2010;10:20.

19. Keys A, Karvonen MJ, Kimura N, Fidanza F, Taylor HL. Indexes of relative weight and obesity. J Chron Dis 1972;25:329-343.

20. Romo M, Koskenvuo M, Kaprio J, Langinvainio H, Pulkkinen P. Incidence and prognosis of ischemic heart disease with respect to geographical area. An epidemiological study of middle-aged Finns. Acta Med Scand 1982;212:355-360.

21. Puska P, Mustaniemi H. Incidence and presentation of myocardial infarction in North Karelia, Finland. Acta Med Scand 1975;197:211-216.

22. Insam C, Paccaud F, Marques-Vidal P. The region makes the difference: disparities in management of acute myocardial infarction within Switzerland. Eur J Prev Cardiol 2014;21:541-548. 
23. Dondo TB, Hall M, Timmis AD, Yan AT, Batin PD, Oliver G, et al. Geographic variation in the treatment of non-ST-segment myocardial infarction in the English National Health Service: a cohort study. BMJ Open 2016;6:e011600.

24. Puymirat E, Battler A, Birkhead J, Bueno H, Clemmensen P, Cottin Y et al Euro Heart Survey 2009 Snapshot: regional variations in presentation and management of patients with AMI in 47 countries. Eur Heart J Acute Cardiovasc Care 2013;2:359-370.

25. Sokoloff A, Lefevre G, Teixeira N, Puymirat E, Beygui F, Vanzetto G et al [Characteristics and management of ST-elevation myocardial infarction in France: Regional variations in 2010]. Ann Cardiol Angeiol (Paris). 2015;64:427-433.

26. Bechtold D, Salvatierra GG, Bulley E, Cypro A, Daratha KB. Geographic variation in treatment and outcomes among patients with AMI: Investigating urban-rural differences among hospitalised patients. J Rural Health 2017;33:158-166.

27. De Luca G, Petrelli A, Landriscina T, Gnavi R, Giammaria M, Costa G. Geographic and socioeconomic differences in access to revascularisation following acute myocardial infarction. Eur J Public Health 2016;26:760-765.

28. Odoi EW, Nagle N, Roberson S, Kintziger KW. Geographic disparities and temporal changes in risk of death from myocardial infarction in Florida, 2000-2014. BMC Public Health 2019;19:505.

29. Kim RB, Kim HS, Kang DR, Choi JY, Choi NC, Hwang S et al The trend in incidence and casefatality of hospitalised acute myocardial infarction patients in Korea, 2007 to 2016. J Korean Med Sci 2019;34:e322.

30. Blais C, Hamel D, Rinfret S. Impact of socio-economic deprivation and area of residence on access to coronary revascularisation and mortality after a first acute myocardial infarction in Quebec. Can J Cardiol 2012;28:169-177.

31. Bucholz EM, Ma S, Normand SL, Krumholz HM. Race, socioeconomic status, and life expectancy after acute myocardial infarction. Circulation 2015;132:1338-1346.

32. Andrikopoulos G, Tzeis S, Terentes-Printzios D, Varounis C, Vlachopoulos C, Mantas I et al Impact of income status on prognosis of acute coronary syndrome patients during Greek financial crisis. Clin Res Cardiol 2016;105:518-526.

33. Patel N, Gupta A, Doshi R, Kalra R, Bajaj NS, Arora G et al In-hospital management and outcomes after ST-segment-elevation myocardial infarction in medicaid meneficiaries compared with privately insured individuals. Circ Cardiovasc Qual Outcomes 2019;12:e004971.

34. Shvartsur R, Shiyovich A, Gilutz H, Azab AN, Plakht Y. Short and long-term prognosis following acute myocardial infarction according to the country of origin. Soroka acute myocardial infarction II (SAMI II) project. Int J Cardiol 2018;259:227-233.

35. Reynolds K, Go AS, Leong TK, Boudreau DM, Cassidy-Bushrow AE, Fortmann SP et al Trends in incidence of hospitalised acute myocardial infarction in the Cardiovascular Research Network (CVRN). Am J Med 2017;130:317-327.

Title and table legends:

Table 1. Regional distributions of different type of myocardial infarctions, medical history, and comorbidities

Legend: In the right column of the results table, the p-value of the Chi-squared test is represented, i.e. whether the value of the examined factors (e.g. the ratio of myocardial infarction) depends on the value of another factor (e.g. in the present case, the region). We then added the post-hoc test results after the p-value in brackets (regionally differentiating between leftover tag values and p-values to show whether the given region is significantly different in terms of frequency from the whole).

Table 2. Patient delay, prehospital response time and types of infarction per region

Table 3. 30-day and 1-year mortality of men and women in different types of myocardial infarction treated with and without PCI, per region

Legend: The first $\mathrm{p}$ value belongs to the chi-squre test, while in brackets the results of the post hoc tests are 
to be found

Title and figure legends:

Figure 1. The regions and their population data

Legend: WR: Western Region, CR: Central Region, ER: Eastern Region

Figure 2.a Time intervals of the emergency care process, NSTEMI

Legend: Arrival to location (T1), treatment on-site (T2) and time interval between transferring the patient from the original location to the hospital (T3)

Figure 2.b Time intervals of the emergency care process, STEMI

Legend: Arrival to location (T1), treatment on-site (T2) and time interval between transferring the patient from the original location to the hospital (T3)

Figure 3. Pharmacological treatment for secondary prevention recommended upon hospital discharge per region.

Legend: WR: Western Region, CR: Central Region, ER: Eastern Region, RAAS: renin-angiotensinaldosterone system, PI: platelet inhibitors

Figure 4. Kaplan-Meier survival curves by regions, NSTEMI

Legend: Survival probabilities (lines and dots) and their confidence intervals (vertical sections) are represented, per region

Figure 5. Kaplan-Meier survival curves by regions, STEMI

Legend: Survival probabilities (lines and dots) and their confidence intervals (vertical sections) are represented, per region

Figure 6. Results of Cox Proportional Hazards Regression Model, NSTEMI

Legend: First column contains names of variables (the factors examined), second column shows the mortality period, third and fourth column show hazard ratio (HR) values in diagram and in tabulated formats (hazard ratio denoted by with square and their confidence intervals denoted by horizontal lines), fifth column shows the probability $(\mathrm{P})$ values (a variable was significant where $\mathrm{P}$ value was below 0.05 , it is denoted by 0 )

Figure 7. Results of Cox Proportional Hazards Regression Model, STEMI

Legend: First column contains names of variables (the factors examined), second column shows the mortality period, third and fourth column show hazard ratio (HR) values in diagram and in tabulated formats (hazard ratio denoted by with square and their confidence intervals denoted by horizontal lines), fifth column shows the probability $(\mathrm{P})$ values (a variable was significant where $\mathrm{P}$ value was below 0.05 , it is denoted by 0 )

\section{Hosted file}

Table 1.docx available at https://authorea.com/users/423131/articles/528672-incidence-prehospital-delay-and-prognosis-of-acute-myocardial-infarction-in-hungary-population-datafrom-the-hungarian-myocardial-infarction-registry

\section{Hosted file}

Table 2.docx available at https://authorea.com/users/423131/articles/528672-incidence-prehospital-delay-and-prognosis-of-acute-myocardial-infarction-in-hungary-population-datafrom-the-hungarian-myocardial-infarction-registry

\section{Hosted file}


Table 3.docx available at https://authorea.com/users/423131/articles/528672-incidence-prehospital-delay-and-prognosis-of-acute-myocardial-infarction-in-hungary-population-datafrom-the-hungarian-myocardial-infarction-registry

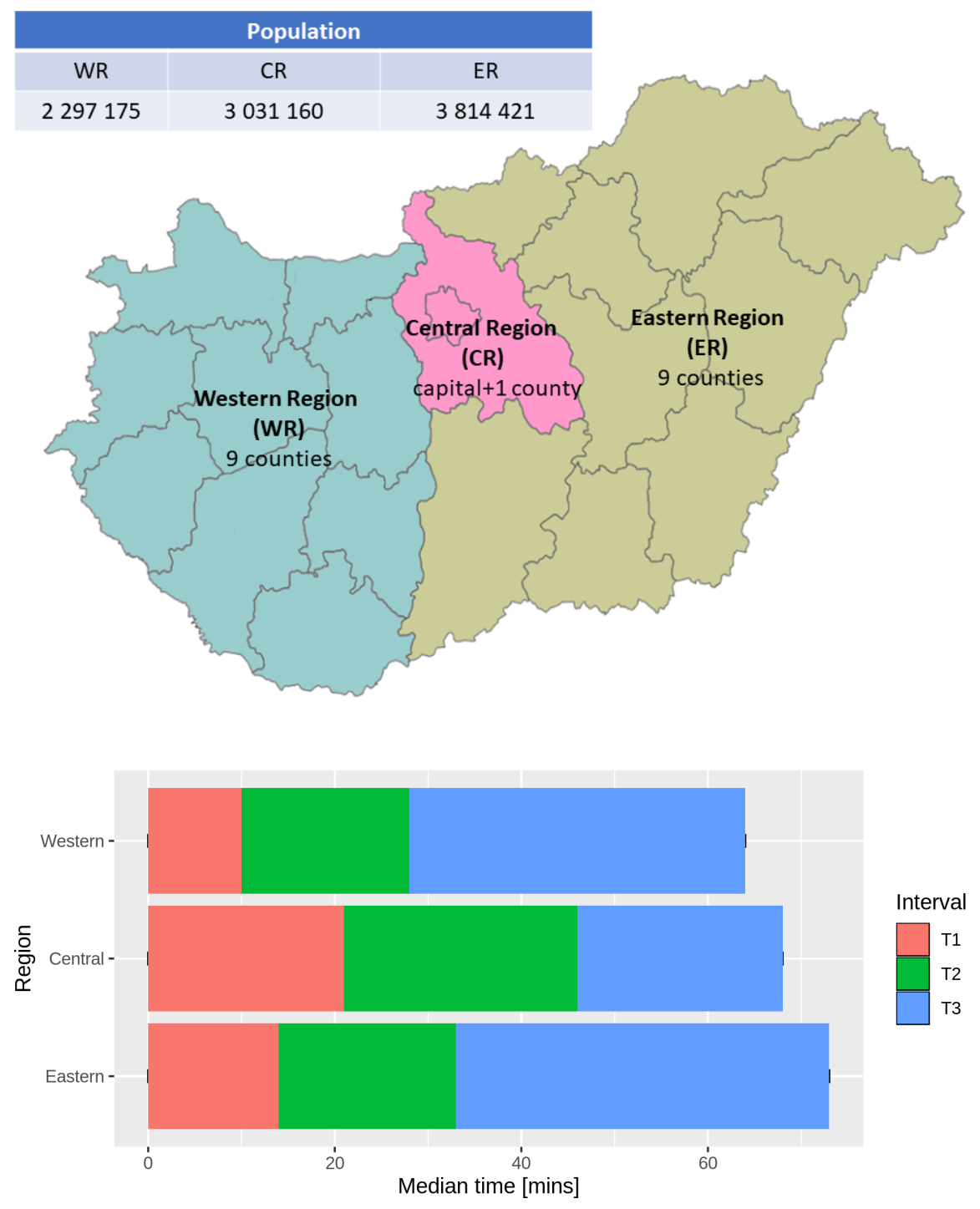




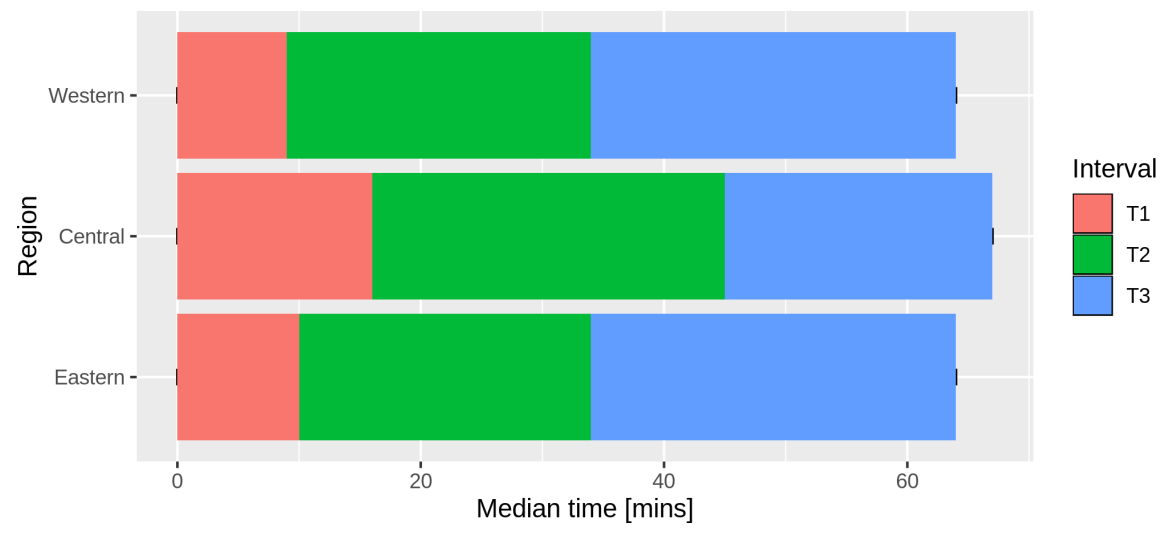

NSTEMI

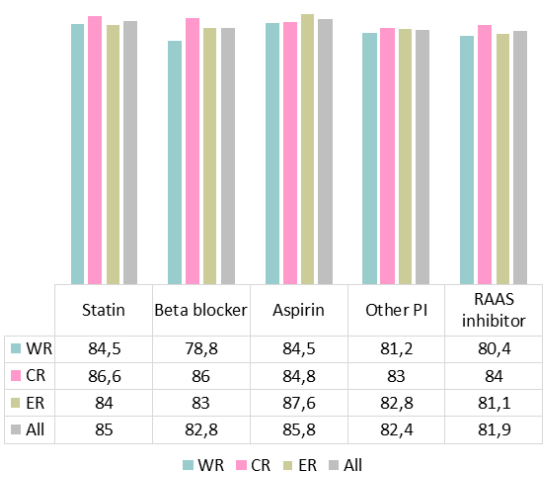

STEMI

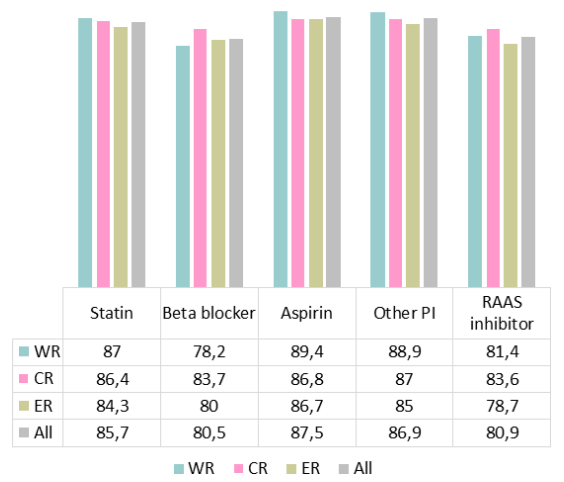




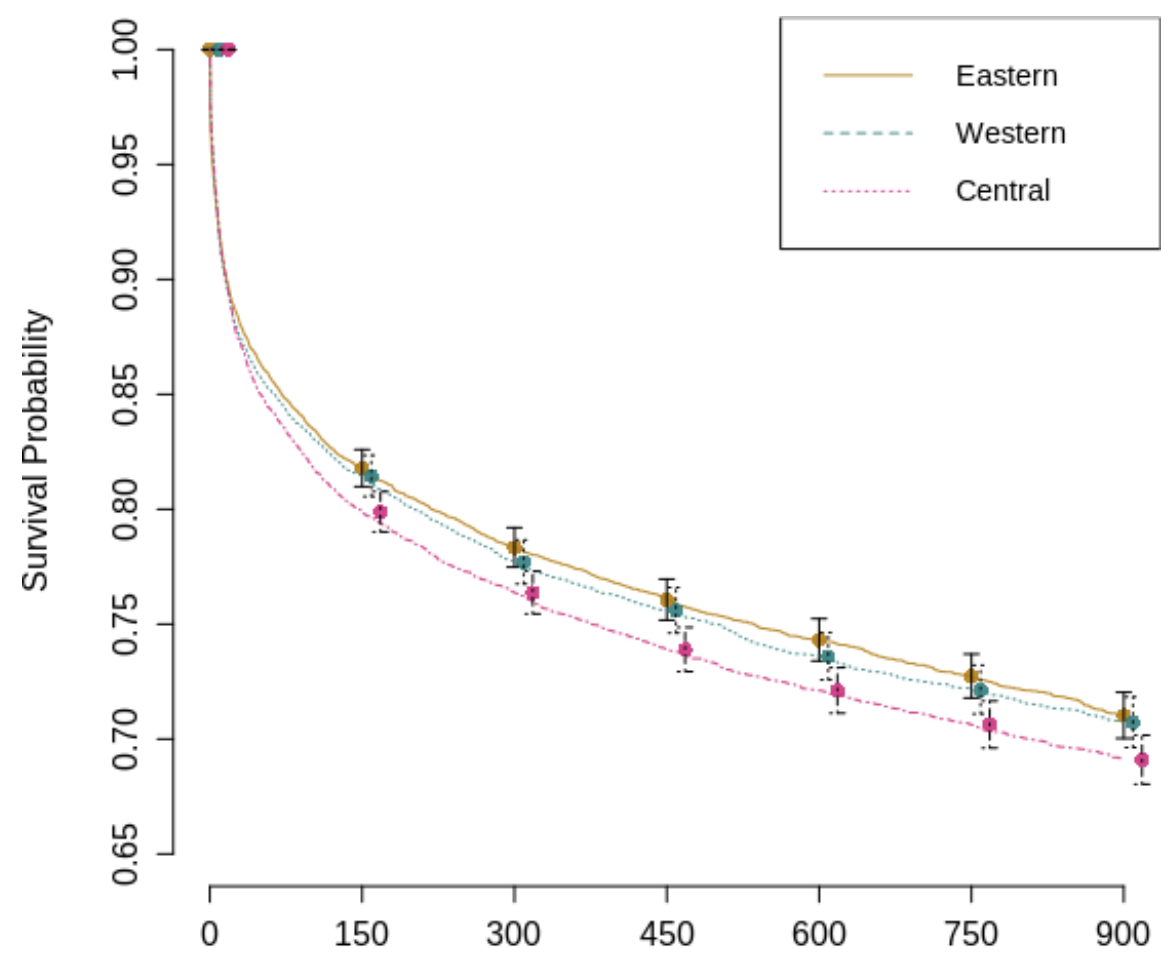

Follow-up time [days]

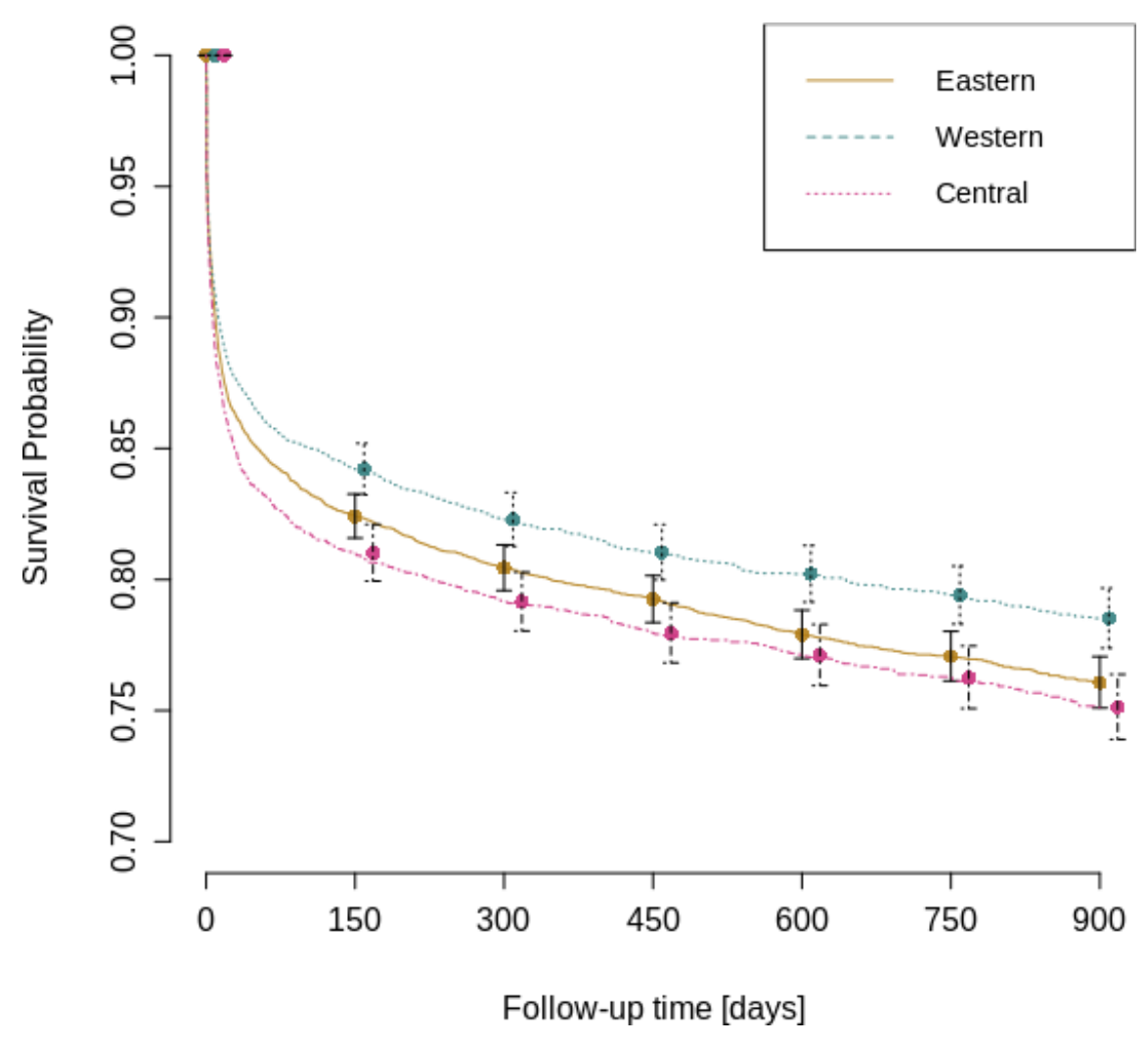




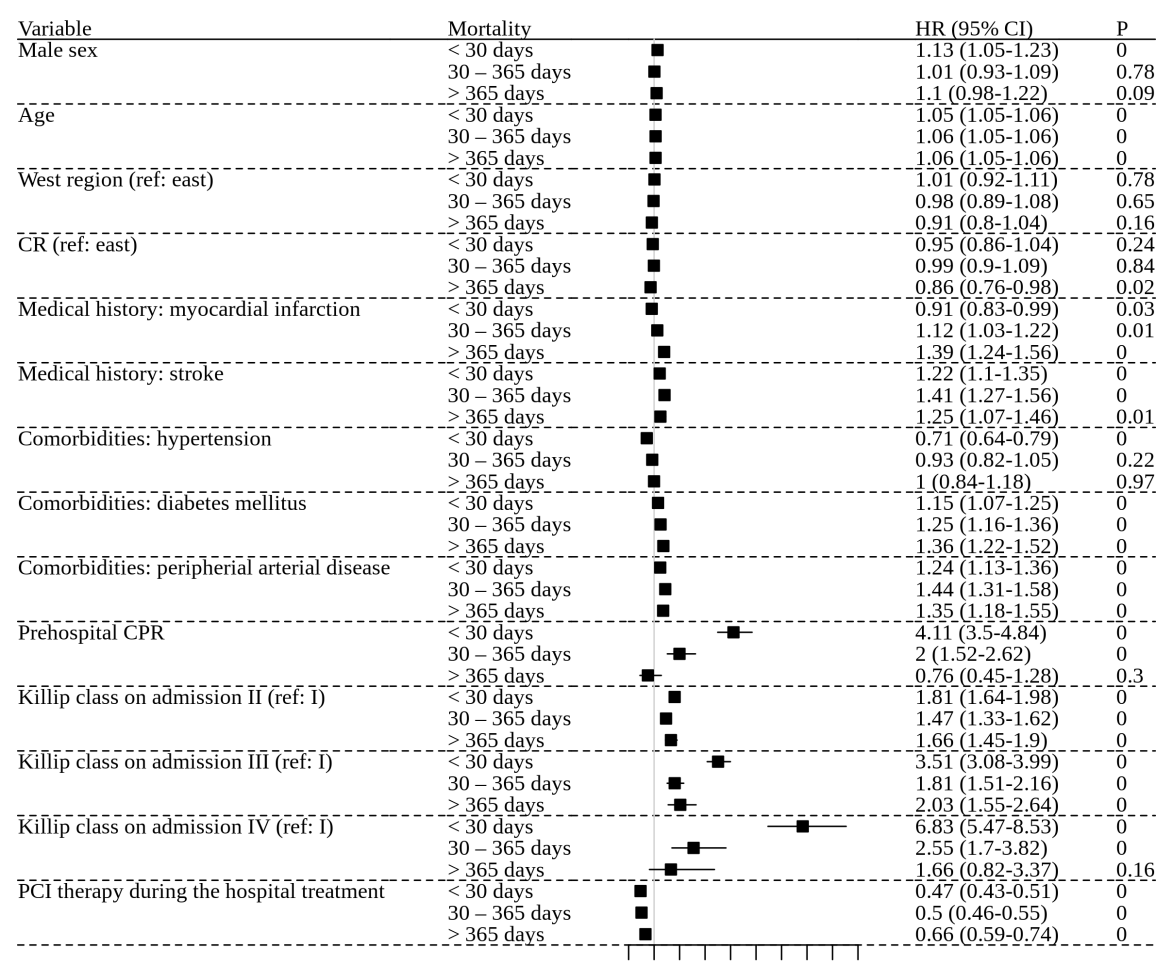

$\begin{array}{llllllllll}0 & 1 & 2 & 3 & 4 & 5 & 6 & 7 & 8 & 9\end{array}$

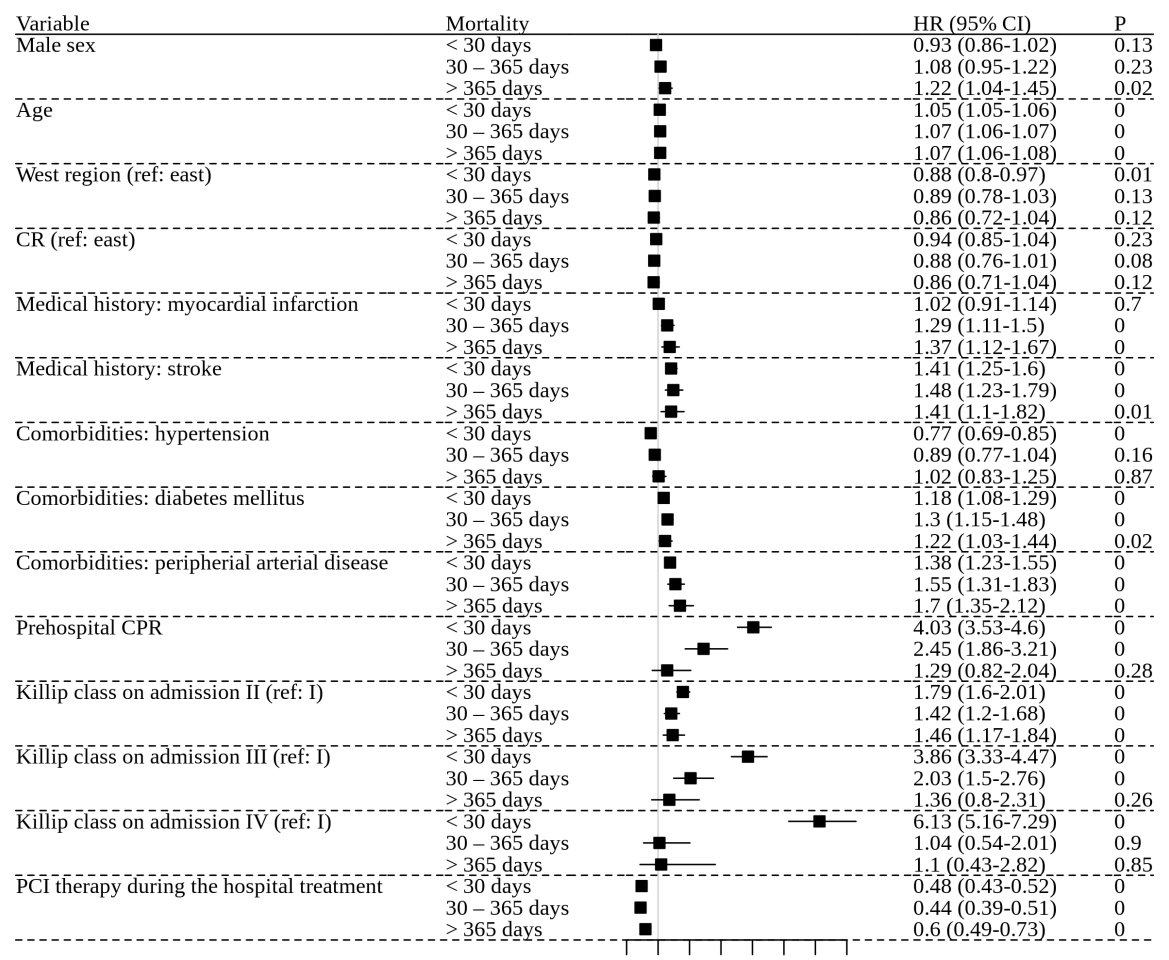

$\begin{array}{llllllll}0 & 1 & 2 & 3 & 4 & 5 & 6 & 7\end{array}$ 